\title{
Canada's contribution to respiratory physiology and pathophysiology
}

\author{
Peter T Macklem MD
}

$I_{\text {tio }}^{\text {to }}$

$\mathrm{t}$ is an almost impossible task to describe Canadian contributions to respiratory physiology and pathophysiology. There have been so many and they have been so important that it is difficult to pick and choose. Inevitably, there will be omissions; inevitably, some of us will not be pleased; and inevitably, one is biased by one's own experience. This will affect what I write, no matter how much I strive for objectivity. I apologize to anyone whose contributions I should have described but failed to do so. And to those whose work I do describe, I hope I have got it right.

The focus of the present review is on the roots of respiratory physiological and pathophysiological research in Canada, and how this led to a contribution to the world literature far greater than what one might predict from our small population. While this legacy is still as strong today, only rarely do I refer to papers published in the past 25 years. The seeds planted in the late 1920s and early 1930s grew rapidly in the 1950s and came into full bloom in the 1960s and 1970s. The present story is about this period, and it is a story about individuals and places, as much as it is about the vast amount of new knowledge that was created. Fortunately, the flowers are perennials and the garden is more beautiful than ever, but that is another story.

The beginnings: Jonathon Meakins and Ronald Christie, along with Joe Doupe and Reuben Cherniack

The roots of Canadian excellence in respiratory physiology and pathophysiology can be traced to two extraordinary men: Jonathon Meakins and Ronald Christie.

Dr Jonathon Meakins was recruited to McGill University (Montreal, Quebec) when, shortly after the First World War ended, Sir William Osler, then Regius Professor of Medicine at Oxford University (Oxford, England) and a graduate of McGill University, recommended that McGill University should hire a full-time Professor of Medicine. As a result, Dr Meakins arrived in Montreal in 1924 as Canada's first full-time Chairman of Medicine and Physician-in-Chief of the Royal Victoria Hospital. His mandate was to establish research in his hospital department as an essential part of academic medicine. Unfortunately, he did not have any laboratory space. So, in what must have been an exceptionally bloody battle, he wrested control of the clinical biochemistry and hematology diagnostic laboratories from the Department of Pathology, which provided his department with the necessary infrastructure to fulfill his mandate.

In 1927, he attracted Dr Ronald Christie to work with him as a resident in medicine. Christie remained at the Royal Victoria Hospital for seven years. With Meakins, it was natural that clinical research was part of his training program, and as a result, Christie published a series of classical papers in respiratory medicine. As shown in Figure 1, he was one of the first to make sense out of the subdivisions of lung volume (1). He measured pleural pressure in normal subjects (Figure 2), as well as in patients with congestive heart failure (Figure 3) and emphysema, and showed that emphysema was characterized by loss of lung elastic recoil (2-4). Research in respiratory physiology and pathophysiology began in Canada.

Joe Doupe was a physiologist at the University of Manitoba, Winnipeg, Manitoba. He was an original thinker and passed on his ideas to medical students and residents. The influence he had on graduates of the University of Manitoba is legendary. Never, at least in Canada, has one man had such an extraordinary record in producing outstanding clinical investigators who became world-renowned in their field. Through these leaders, Doupe has had an enormous impact on medicine in Canada. Henry Friesen, John Dirks, the Hollenbergs, Arnold Naimark, Aubie Angel, Jim Hogg, Garth Bray and Barry Posner, to name a few, all owe a great deal to Joe Doupe. But this story is about Joe Doupe's influence on Reuben Cherniack. Quite independently of what was going on in Montreal, Reuben founded a hugely successful program in respiratory and intensive care medicine in Winnipeg. Here is what Arnold Naimark has to say about Reuben:

They say that, for retail enterprises the three most important success factors are location, location, location. Well for the development of excellence in respiratory disease in Manitoba - the three most important success factors were Reuben, Reuben, Reuben. He was the sparkplug that inspired me and many of my contemporaries to pursue academic careers in respiratory medicine. He was our taskmaster, champion and friend. He was an instigator, builder, developer and innovator - impatient with bureaucracy, generous in sharing credit for achievement and with a keen eye for spotting and nurturing talent.

It doesn't require many degrees of separation to trace Reube's influence in the careers of people engaged not only in adult respiratory medicine but also in pediatrics (Chernick and Rigatto), in intensive care (Brian Kirk et al) in anesthesiology and in respiratory physiology both clinical and cellular (Naimark, Stephens, Kroeger, Halayko). Add to this the folk he recruited (Younes, Anthonisen, Mink, Kryger et al) and the trainees who located and made their mark elsewhere...

Meakins-Christie Laboratories, McGill University Health Centre Research Institute, Montreal, Quebec

Correspondence: Dr Peter T Macklem, PO Box 250, Lansdowne, Ontario KOE 1LO. Telephone/fax 613-659-2001, e-mail peter.mackem@gmail.com 


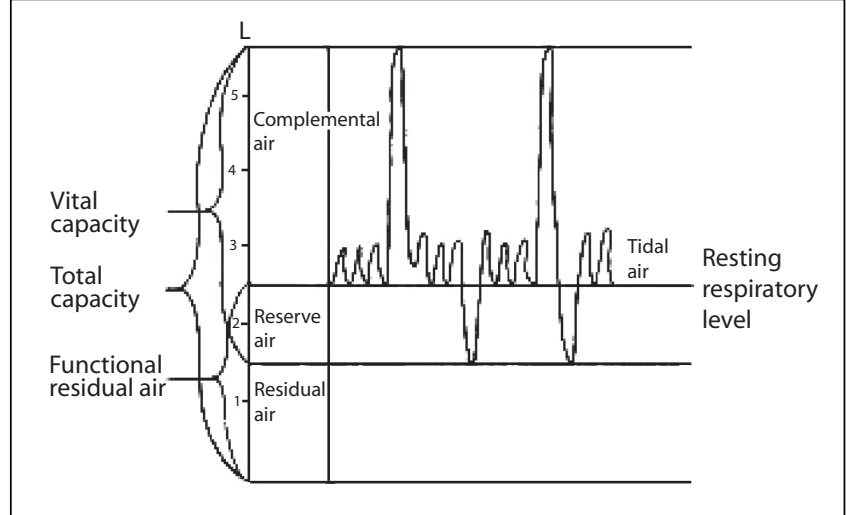

Figure 1) The subdivisions of lung volume as described by Ronald Christie in 1932. Reproduced with permission from reference 1

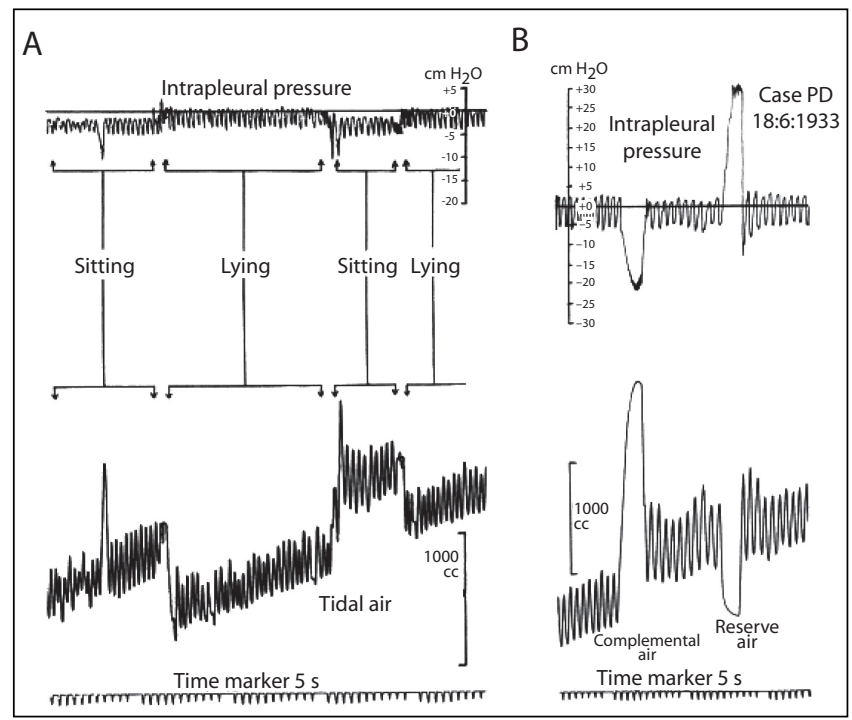

Figure 2) A Ronald Christie's measurements of pleural pressure in a normal subject sitting upright and supine. B Pleural pressure in a normal subject during a deep inspiration to total lung capacity followed by a breath out to residual volume. Both figures are reproduced with permission from reference 2

Reube... brought together a fully integrated respiratory medicine program embracing laboratories (both clinical pulmonary function testing and experimental labs for humans and animals), a respiratory critical care unit and inhalation therapy service with links to clinical teaching units on the wards... I (still) attend chest rounds on a regular basis - and if nothing else they serve to remind me of how the lengthened shadow of Reube's influence has extended through the decades.

Meakins and Christie in Montreal, and Doupe and Cherniack in Winnipeg, are the roots of Canadian excellence in respiratory physiology and pathophysiology.

\section{Montreal}

After leaving Montreal, Christie took up an academic appointment at St Bartholomew's Hospital Medical School in London, England, and rose to the rank of Professor and Chairman. In 1955, he was recruited back to McGill University and, like Meakins before him, was appointed as

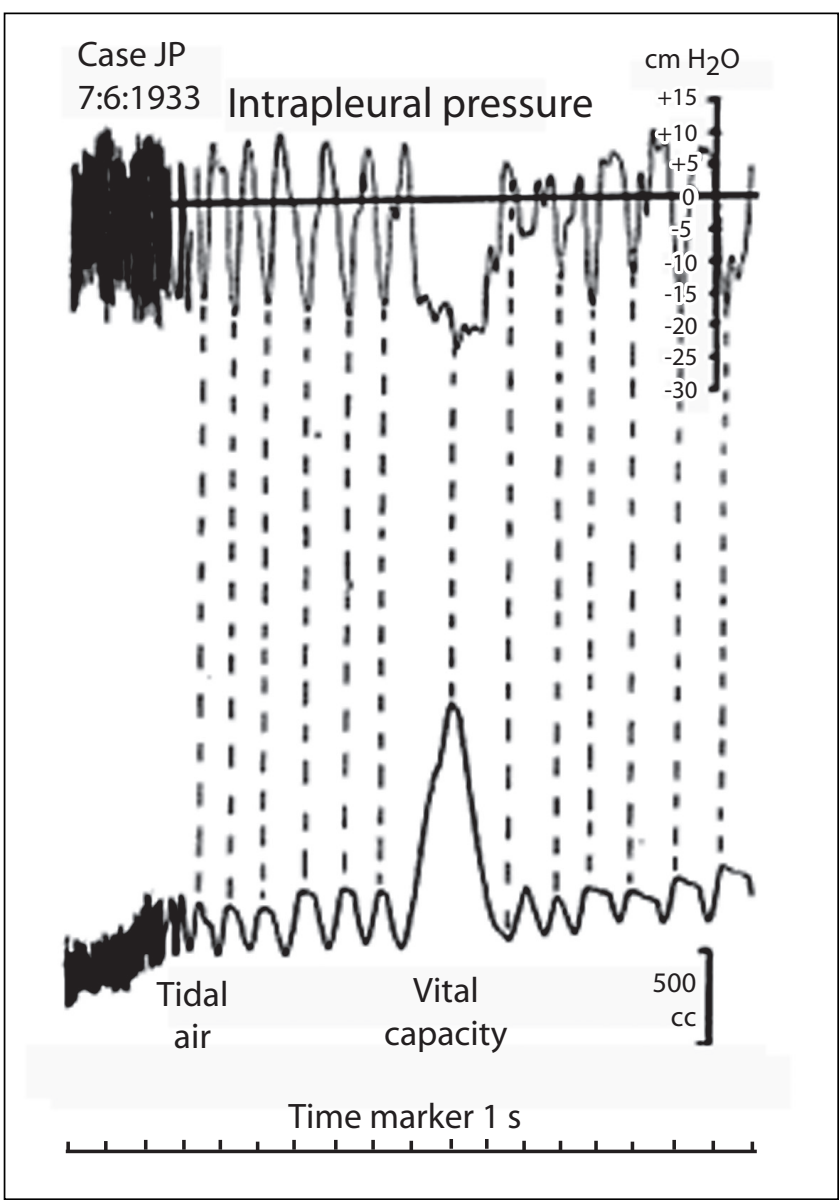

Figure 3) Ronald Christie's tracings of pleural pressure in a patient with congestive heart failure. Note that tidal pressure swings, closely in phase with tidal volumes of approximately $360 \mathrm{~mL}$, are approximately $30 \mathrm{~cm} \mathrm{H}_{2} \mathrm{O}$ giving a dynamic compliance of only $0.012 \mathrm{~L} / \mathrm{cm} \mathrm{H}_{2} \mathrm{O}$. To my knowledge, this is the first demonstration of stiff lungs in heart failure. Reproduced with permission from reference 4

Physician-in-Chief of the Royal Victoria Hospital and Chairman of the Department of Medicine. I was a final year medical student at the time, and I well remember attending a professorial lecture that he gave shortly after his arrival. He talked about lung compliance and resistance, and how the two determined the work of breathing. He showed how, for a given level of ventilation, these parameters changed with changes in breathing frequency and tidal volume, and that there was a particular ventilatory pattern that resulted in minimal work. Minimal work in airways obstruction was shown to be a slow deep breathing pattern, whereas if the lungs were stiff, a rapid shallow breathing pattern was optimal (5). This lecture had a huge influence on me. Although it was still several years before I decided that respirology was my calling, there is no doubt that Christie's lecture played an important role in that decision.

Christie brought David Bates with him to McGill University. When they arrived, there was already a strong respiratory medicine program in place, with Peter Pare in the Department of Medicine, Bob Fraser in radiology and Dag Munro in surgery. Soon Bates and Christie recruited many more doctors. Margot Becklake and Maurice McGregor came from South Africa. So did William 'Whitey' Thurlbeck via Harvard University (Boston, Massachusetts), who took 


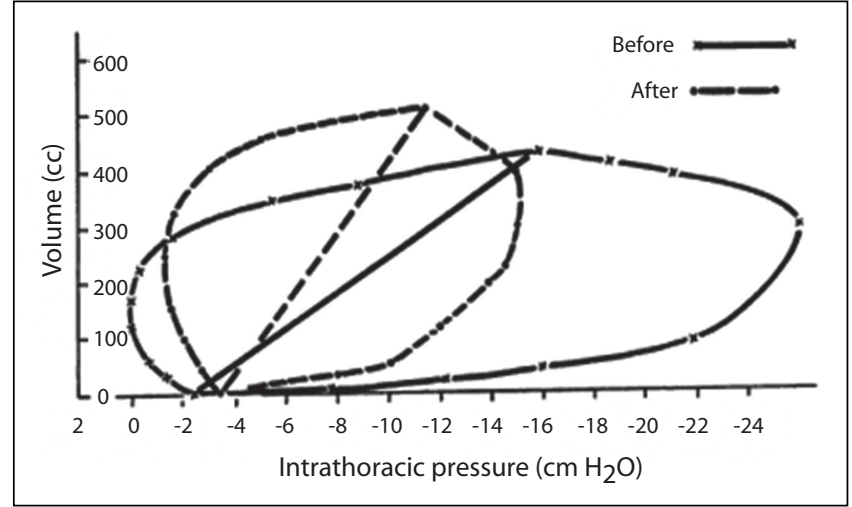

Figure 4) Reuben Cherniack's dynamic pressure-volume loops measured before and after bronchodilators in a patient with emphysema and cor pulmonale. Reproduced with permission from reference 6

up an appointment in the Department of Pathology. Joseph Milic-Emili came from Harvard University to join the Department of Physiology. Somewhat later, Nick Anthonisen came from Dartmouth College (Hanover, New Hampshire). It was an exciting time.

\section{Winnipeg}

Concurrently, Reuben Cherniack was developing a strong respiratory program in Winnipeg. Reuben wrote:

It was Joe Doupe's influence in setting an example of... enquiry and the need for justification of conclusions based on data. As part of my medical residency I spent 6 months carrying out a project on peripheral vascular disease.

On completion of the chief residency I decided to become a neurologist and looked for a fellowship, and one day got a call from brother Lou about a position in New York. I accepted quickly and then found it was in pulmonary disease with Dr. Alvan Barach.

A number of events set the flavor for the ultimate activities of the pulmonary unit in Winnipeg:

- During the exciting year at Columbia with Barach, the 'Green Journal' published an excellent series of essays by Wallace Fenn, Julius Comroe and Richard Riley.

- I applied to Rochester and had an hour-long interview with Fenn who said he would accept me but recommended that I go with Riley, since my interests were very patient oriented.

- When I arrived at Hopkins, Riley said they didn't study mechanics but I could set up the necessary equipment if I wanted to. Which I did along with participating in studies of gas exchange.

- For the following year I was slated to go to Barts to work with Ronald Christie, but later that year he wrote that he was moving to McGill and invited me to join him there.

- I was awarded a Markle fellowship which allowed me to go to London for six months (really a vacation tour of Europe).

- I got a letter from... (Moran Campbell) at Middlesex stating that he had inherited my mechanics setup while at Hopkins, had heard I was coming to London, and offered to help.

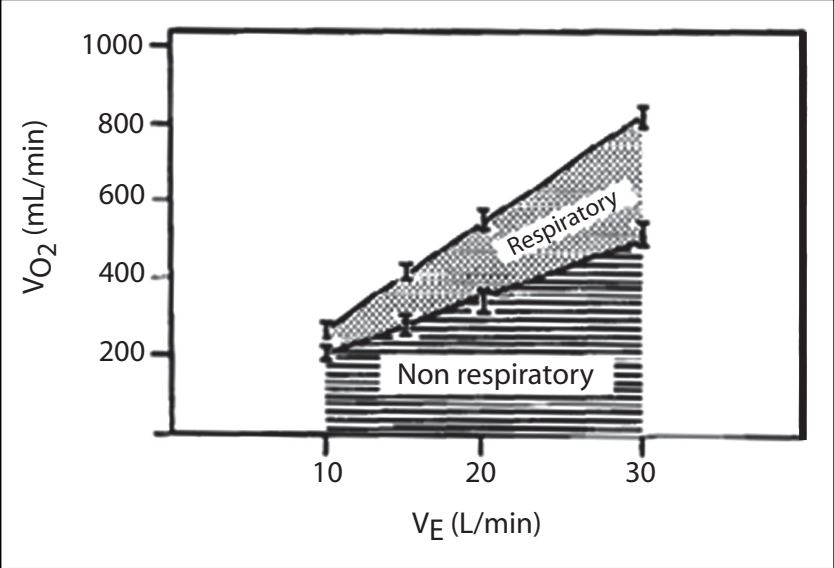

Figure 5) Reuben Cherniack's and Henry Levison's classic diagram showing that the oxygen $\left(\mathrm{O}_{2}\right)$ cost of breathing was a large component of total body $\mathrm{O}_{2}$ consumption during exercise in patients with chronic obstructive pulmonary disease. Means and standard errors are shown. Reproduced with permission from reference $9 . \mathrm{V}_{\mathrm{O}_{2}}$ Oxygen uptake; $V_{E}$ Minute ventilation

- Edy (very pregnant) (Reube's wife) and I went to London where Karen was born. While Edy was in hospital Moran and I hit the pubs where we came up with the idea of studying the oxygen consumption and efficiency of the respiratory muscles.

- The polio epidemic got me very involved with critical care and ventilator management and then the home care program.

All in all I have been lucky to be in the right place at the right time and particularly blessed by the bright fellows such as Arnold Naimark, Newman Stevens, and later Larry Wood, to name a few, who did all the work while I got the credit.

The early research that Reuben did, and his collaboration with Moran Campbell in London (who, approximately 10 years later, came to McMaster University [Hamilton, Ontario] as the founding chairman of the Department of Medicine) are classical. He investigated the physical properties of the lungs in patients with emphysema and found that they were hypercompliant except, as shown in Figure 4, in the presence of cor pulmonale (6) when they were stiffer than normal. Note that it took approximately $14 \mathrm{~cm} \mathrm{H} O$ to inflate the lung by $400 \mathrm{~mL}$, giving a dynamic compliance of only approximately $0.03 \mathrm{~L} / \mathrm{cm} \mathrm{H}_{2} \mathrm{O}$, whereas after bronchodilators, the dynamic compliance increased fivefold to approximately $0.150 \mathrm{~L} / \mathrm{cm} \mathrm{H}_{2} \mathrm{O}$. To the best of my knowledge, this interesting finding that the lungs become less compliant when emphysema is complicated by right heart failure and that this condition may respond to bronchodilators, has not been further investigated.

With Moran Campbell, Reuben developed a method to measure the oxygen $\left(\mathrm{O}_{2}\right)$ cost of breathing and the efficiency of the respiratory muscles (7). He applied this method to patients with emphysema and showed that the $\mathrm{O}_{2}$ cost was much higher than normal and that this might limit exercise in chronic obstructive pulmonary disease (COPD) patients (8). Ten years later, Reuben and Henry Levison published their classic paper on the ventilatory cost of exercise in COPD patients (9). Figure 5 illustrates the main message of this paper, namely 
that the $\mathrm{O}_{2}$ taken up by the respiratory muscles was a large percentage of the total $\mathrm{O}_{2}$ consumption at the cost of reducing the $\mathrm{O}_{2}$ available to the working locomotor muscles. This, he claimed, must be an important factor limiting exercise. While everyone remembers that the $\mathrm{O}_{2}$ cost of breathing is much greater than normal in COPD patients, the message that this is an important factor limiting exercise in this disease has been largely ignored or forgotten until recently when it was rediscovered by others who (mea culpa) did not give credit to Reuben for his original observation (10).

With Bates and Christie in Montreal, and Cherniack in Winnipeg, research into respiratory physiology and pathophysiology rapidly expanded.

\section{David Bates and contributions from McGill University}

David Bates had the brilliant idea that regional lung function could be investigated by breathing radioactive gases. After he gave a Grand Rounds to the Department of Medicine at Johns Hopkins University (Baltimore, Maryland), the Department realized it should expand its respiratory medicine program (Dick Riley was not in the Department of Medicine), and so they sent their Chief Resident, Will Ball, to David to do a research fellowship under his supervision. David put Will to work on using xenon-133 ( $\left.{ }^{133} \mathrm{Xe}\right)$ to study regional lung function. They had subjects breathe ${ }^{133} \mathrm{Xe}$ and measured where it went in the lung by external scintillation counters. They also dissolved ${ }^{133} \mathrm{Xe}$ in saline and injected it intravenously so that when it left the pulmonary capillaries and entered the alveoli, they had a measurement of perfusion distribution. The problem was that although they could demonstrate regional differences in scintillation counts due to ${ }^{133} \mathrm{Xe}$ in the lung, they did not know the concentration represented by the counts. The key to making ${ }^{133} \mathrm{Xe}$ studies of regional lung function quantitative was to rebreathe ${ }^{133} \mathrm{Xe}$ until it was equilibrated. This gave a known concentration for a given scintillation count; the regional counts were expressed as a percentage of the equilibration concentration (11).

After Will Ball returned to Johns Hopkins University, Charlie Bryan came and obtained a $\mathrm{PhD}$ under David using ${ }^{133} \mathrm{Xe}$ to continue the studies of regional lung function. Charlie wondered why most of the inhaled ${ }^{133} \mathrm{Xe}$ went to dependent lung regions and less went to superior ones. At a spring Federation of American Societies for Experimental Biology meeting, Walt Daly and Stuart Bondurant presented a paper in which they measured regional pleural pressure swings in humans by putting needles into the pleural space near the base and the apex. The basal pleural pressure swings were greater than the apical ones, and Charlie believed he had his answer. Walt and Stuart were invited to bring their needles to Montreal so that ${ }^{133} \mathrm{Xe}$ distribution and regional pleural pressure swings could be measured simultaneously. "But who will the subjects be?", I innocently asked Charlie. "I'll be one and you'll be the other," he replied. Gulp!

The terrifying day finally arrived. Everything was ready. The needle went into my left pleural space behind my heart. I immediately went into acute psychogenic heart failure with loud stertorous breathing. The needle was removed but nothing else changed. Charlie, a brilliant clinician that he was, noticed that my neck veins were sky high. They pushed the panic button for our hospital's latest innovation, the cardiac arrest team. The button did not work and failed to ring. I was rushed to the Radiology Department where I suddenly recovered. My psychogenic heart failure was a severe case of laryngospasm. You would think that might be the end of it, but no; this was long before the days of ethics committees. Charlie was the next subject. In went the needle. "Ouch!”, went Charlie. The needle was inserted into an area where there were pleural adhesions. Before coming to Montreal, Charlie had been in the Royal Canadian Air Force, where he was repeatedly a subject for experiments with explosive decompressions. I have seen a movie of him during one of these episodes where he lost consciousness and convulsed. One time, he actually had a straight line electroencephalogram recorded. Another time, he aspirated and got a lung abscess. This caused the adhesions, which caused our experiment to be a spectacular failure. A terrible day scientifically, but a very successful binge afterwards.

In spite of this disaster, Charlie published an important paper describing the effects of posture, exercise, induced syncope and breathing $100 \% \mathrm{O}_{2}$ on the regional distribution of ventilation and perfusion in the lung (12). After completing his $\mathrm{PhD}$, Charlie returned to Toronto, Ontario, and the Hospital for Sick Children, where he became renowned for his contributions to pediatric intensive care. His most important work was the demonstration of the safety and efficacy of high frequency ventilation in infants (13-17). This was controversial due to the failure of the National Institutes of Health $\mathrm{HiFi}$ trial, probably because at some centres, recruitment of lung volume before instituting high-frequency ventilation was not properly performed. Charlie and his co-worker, Allison Froese, an anesthetist now at Queen's University (Kingston, Ontario), persisted, publishing at least 20 peer-reviewed papers on almost every aspect of high-frequency ventilation in infants. As a result, it has now received worldwide acceptance as an effective means of ventilating infants with acute respiratory distress syndrome.

After Charlie left McGill University, Joseph Milic-Emili was recruited to the Department of Physiology from the Harvard School of Public Health (Boston, Massachusetts), where he eventually became the chairman of the department. He continued the investigation of the regional distribution of ventilation and perfusion in the lung with ${ }^{133}$ Xe. Milic-Emili applied classical respiratory physiology to the regional distribution of lung volume by measuring regional lung volumes from apex to base and from total lung capacity to residual volume as a function of overall lung volume changes in the upright, supine, prone and lateral decubitus postures $(18,19)$. This resulted in his famous onion-skin diagram, as shown in Figure 6, for the upright posture. At total lung capacity, there was no gradient in regional volume between apex and base, but at all lower volumes the apex was more inflated than the base. However, below functional residual capacity the base stopped emptying while the apex continued to do so (18). This was attributed to airway closure in dependent lung regions, and the groundwork for closing volume and closing capacity was set (20). Milic-Emili and Charlie collaborated to show that virtually all of the gradient in lung volume was due to the effect of gravity on the lung (21) and calculated that the gravitydependent gradient in pleural pressure was approximately $0.25 \mathrm{~cm} \mathrm{H}_{2} \mathrm{O} / \mathrm{cm}$ descent, which increased systematically with increasing gravitational force.

While all this was going on, Nick Anthonisen arrived at the Royal Victoria Hospital from Dartmouth College for residency training in respiratory medicine. It did not take him long to discover that patients with pulmonary edema often 
developed hypercapnic pulmonary edema (22). He followed his residency program with a research fellowship and then joined the attending staff of the Department of Medicine as a clinician scientist. He promptly developed a steady-state method for measuring regional ventilation to perfusion ratios with ${ }^{133} \mathrm{Xe}$ (23), and made the first systematic measurements of regional lung function in disease (24-26). Nick made many contributions to respiratory pathophysiology at McGill University, followed by a move to the University of Manitoba where he continued his distinguished career, culminating in his appointment as Dean of the Faculty of Medicine.

Quite a different aspect of regional lung function was investigated when Jim Hogg, at Charlie Bryan's suggestion, came to McGill University to do a $\mathrm{PhD}$ under the joint direction of Whitey Thurlbeck and myself. We planned to train him in both physiology and morphometry, and develop someone uniquely capable of covering the whole field of respiratory structure and function. We succeeded and we certainly picked the right man. Jim applied the retrograde catheter technique to measure pressure in small airways to human lungs explanted at autopsy. He confirmed that in normal lungs, the small airways only constituted a small fraction of the total flow resistance in the lung, and found that in the lungs of patients with COPD, the site of obstruction was in the peripheral airways (27). He discovered that there was little resistance to collateral ventilation in emphysema and that the flow resistance of the collateral channels was less than airway resistance (28). This was a novel finding, the implications of which are now being developed 40 years later as a promising new treatment of emphysema (29). He froze lungs from intact animals, measured the gravity-dependent gradient in lung density, and from that, deduced the pleural pressure gradient in much the same way that Milic-Emili had done in humans with ${ }^{133} \mathrm{Xe}$. Now he has applied an identical method using Houndsfield units to quantify regional lung morphometry from computed tomography scans (30).

Jim's findings that the resistance of peripheral airways was normally only a small component of the total, whereas in COPD, it was the major site of obstruction, raised the question of how to detect early airways obstruction in small airways before it became advanced. The small airways were a quiet zone where there could be a lot of pathology with little measurable pathophysiology (31). This led to a spate of Canadian papers on the early detection of small airways obstruction over the next 10 years $(19,32-40)$.

\section{Reuben Cherniack and contributions from the University of Manitoba}

Meanwhile, back on the Prairies, Reuben was building a strong respiratory group in Winnipeg. With Bryan Kirk, he established Canada's first intensive care unit, which for well over a decade stood as a model for the rest of the country and internationally. Reuben stimulated Arnold Naimark's interest in respiration. Arnold wrote:

After internship I did an MSc with Reube and with his help and encouragement went to the CVRI at UCSF from 1960-62 where I worked with Malcolm McIlroy, Karl Wasserman, Dick Havel and indirectly with John Clements. From the CVRI to Hammersmith for a year where I worked with Moran Campbell and John West. Then back to Manitoba in 1963 to join Reube and pursue my interests in respiratory physiology at the organ

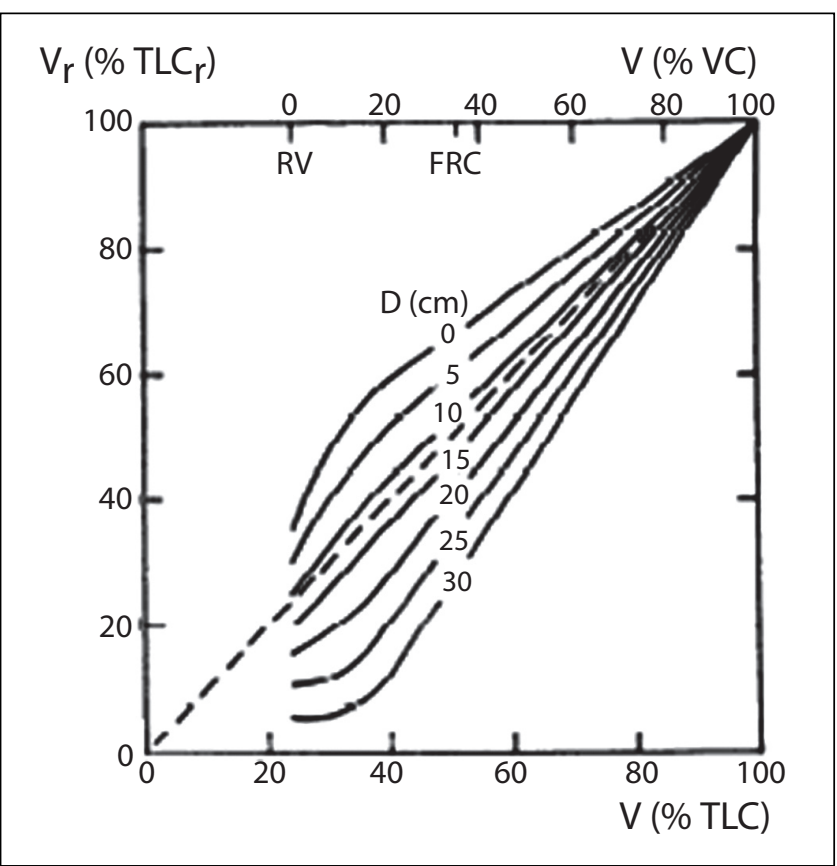

Figure 6) Milic-Emili's famous onion skin diagram. Reproduced with permission from reference 19. D Distance; FRC Functional residual capacity; RV Residual volume; TLC Total lung capacity; TLC $_{r}$ Regional total lung capacity; V Overall lung volume; VC Vital capacity; $V_{r}$ Regional lung volume

system and cellular level (distribution of pulmonary blood flow, exercise, and phospholipid metabolism in the lung). By that time Reube had brought together a fully integrated respiratory medicine program embracing laboratories (both clinical pulmonary function testing and experimental labs for humans and animals), a respiratory critical care unit and inhalation therapy service with links to clinical teaching units on the wards etc., etc. By the late 1960's I had taken on the headship of the department of physiology, then in the 70's the deanship and in the $80 \mathrm{~s}$ and $90 \mathrm{~s}$ the presidency of the university with the result that my activities on the respiratory scene became progressively attenuated and ultimately nonexistent. However, I attend chest rounds on a regular basis - and if nothing else they serve to remind me of how the lengthened shadow of Reube's influence has extended through the decades.

Arnold, of course, is one of Canada's most distinguished physician educators whose impact on academia and medicine in Canada has been enormous.

Reuben and Arnold recruited strongly, mostly from McGill University. Whitey Thurlbeck left McGill, went to England and returned to Winnipeg, before ending his career at the University of British Columbia (Vancouver, British Columbia). Nick Anthonisen was recruited as Director of the Respiratory Division and later became Dean of the Faculty of Medicine. While in Winnipeg, his interests grew in clinical epidemiology, and with his colleague, Yuri Manfreda (also recruited from McGill University), made several important contributions to new knowledge in COPD. Nick's involvement culminated in the massive, multicentre National Heart, Lung, and Blood Institute (NHLBI) lung health study for 
which he was Principle Investigator. Magdy Younes, an Egyptian who was trained medically in Cairo, Egypt, did a residency in respiratory medicine at McGill University, a fellowship with Milic-Emili and then via Galveston, Texas, came to Winnipeg, where he made many contributions to respiratory mechanics and the control of breathing. Meir Kryger, a graduate of McGill University and its residency training program, had done research with Nick while both were still in Montreal. He established an outstanding academic sleep laboratory at the University of Manitoba. Larry Wood, who received his $\mathrm{PhD}$ under my direction, returned to his home in Winnipeg as an intensivist and made important studies in acute lung injury, before taking up a position at the University of Chicago, Chicago, Illinois.

Of course not everyone came from Montreal. Newman Stephens came from Johns Hopkins University. In a long and seemingly indestructible career, he is still making advances in our understanding of the physiology and pathophysiology of airway smooth muscle. And he trained and recruited one of the brightest young stars on the Canadian scene today, Andrew Halayko. Long before there was much clinical interest in the subject, Newman applied the classical mechanical properties of muscle measured by others to airway smooth muscle $(41,42)$. This initiated an extraordinary output of new knowledge on the physiology and pathophysiology of airway smooth muscle, which continues unabated to date. When one considers the worldwide interest in airway smooth muscle behaviour in asthma today, it is obvious that Newman was far ahead of his time. And he was there at the beginning when clinical investigators started to investigate the role of airway smooth muscle in asthma (43).

Victor Chernick looked after the pediatric side of things. He trained with Mary Ellen Avery and therefore understood very well that atelectasis resulted from surfactant deficiency. It was therefore necessary to treat infants with the respiratory distress syndrome by recruiting lung volume. He did this by negative pressure applied to the surface of the chest wall, either as the only intervention or combined with mechanical ventilation by intermittent positive pressure breathing $(44,45)$. He showed clearly that continuous negative pressure avoided bronchopulmonary dysplasia, pneumothorax and pneumomediastinum, while intermittent positive pressure alone had a high complication rate that was mitigated by volume recruitment resulting from positive end-expiratory pressure (46). Victor can take a great deal of credit for the remarkable reduction in mortality from the respiratory distress syndrome of infancy, once the number one killer of infants in developed countries, but now no longer a major public health problem. Considering the number of years of life added by conquering the pathophysiology of surfactant deficiency, this must be regarded as one of medicine's greatest triumphs ever.

\section{Moran Campbell and McMaster University}

In 1968, Moran Campbell arrived in Canada from the United Kingdom as the founding chair of the Department of Medicine at McMaster University's new medical school. A new dimension was added to Canada's expanding programs in respiratory physiology and chest disease. In fact, two dimensions were added because Moran brought with him Norman Jones. The dimension that Moran added was psychophysics applied to analyzing and identifying the component parts that constituted the symptom of dyspnea (47-53). He did this largely with Kieran Killian, an Irish émigré to Canada, who resembled
Moran in many ways: Moran's clone as it were. Norman Jones brought with him expertise in exercise physiology.

Norman's text Clinical Exercise Testing, now in its 4th revised edition, has for years set the standard in this field. Norman was the first to show that rebreathing could be used to estimate the mixed venous-arterial partial carbon dioxide content difference at the end of exercise and therefore could be used to estimate cardiac output noninvasively $(54,55)$; he reviewed the physiology of exercise and its clinical applications $(56,57)$, and made important contributions to metabolism during exercise (58-61). Norman and Moran created the respiratory program at McMaster University and made it a power house.

Moran also recruited Freddie Hargreaves from the United Kingdom. Freddie, an immunologist with expertise in allergic lung diseases in general and asthma in particular, was largely responsible for creating a strong asthma research program at McMaster University, which includes such luminaries as Paul O'Byrne and Malcolm Sears who came to Canada after creating an international reputation for himself in New Zealand for his studies on asthma mortality.

\section{Eliot Phillipson and the University of Toronto}

At the University of Toronto (Toronto, Ontario), Eliot Phillipson, a pioneer in sleep-disordered breathing, built a strong program in the Department of Medicine to complement what Charlie Bryan had done in the Department of Pediatrics. A native of Alberta, Eliot received his early training in respirology with Brian Sproule of the University of Alberta (Edmonton, Alberta). He then went to the Cardiovascular Research Institute (CVRI) at the University of California (San Francisco, USA) where, with J Nadel, he studied ventilatory control in conscious dogs. After the CVRI, Eliot was recruited to the University of Toronto where he initiated his studies of breathing and sleep.

Eliot, who credits Comroe for stimulating his research in breathing during sleep, did not publish in this area while at the CVRI: his first publication came from the University of Toronto (62), where he applied the techniques he had learned about control of breathing in conscious dogs to ventilatory control during sleep. Among other factors, he studied chemical control $(63,64)$, and in one stunning paper, he and his colleagues suppressed "the major respiratory stimuli (wakefulness, vagal, peripheral and central chemoreceptors) in healthy, unanesthetized dogs." Slow-wave sleep decreased respiratory rate from 17 breaths/min to 14 breaths/min, and minute ventilation from $8.4 \mathrm{~L} / \mathrm{min}$ to $6.8 \mathrm{~L} / \mathrm{min}$. Afferent vagal blockade during sleep slowed respiratory rate to 4 breaths/min; expiratory time increased to $13.3 \mathrm{~s}$, and minute ventilation decreased to $4.8 \mathrm{~L} / \mathrm{min}$. One breath of $100 \% \mathrm{O}_{2}$ prolonged expiratory time further to 27.4 s. Induction of metabolic alkalosis reduced central chemoreceptor control, which, combined with afferent blockade and hyperoxia, now prolonged expiratory time to as long as $57 \mathrm{~s}$ and reduced respiratory rate to as low as $1 \mathrm{breath} / \mathrm{min}$. These results demonstrated that afferent respiratory stimuli are essential for sustaining adequate ventilation during sleep (65).

A PubMed search for control of breathing during sleep reveals 1742 hits, with Eliot's first paper on the subject (61) being number 1714 . Of the 28 papers published before Eliot's, I could only find two that dealt with the normal breathing pattern during sleep: one was in newborns and the second was in 
the elderly. The Pickwickian syndrome had already been described 20 years previously, but amazingly, no one had set out to systematically study the control of breathing during sleep in health and apply it to sleep-disordered breathing. This long overdue investigation started in Canada with Eliot Phillipson, and he got it right. He justly became renowned for his accomplishments, and in a two-year period, Eliot published three major reviews of the control of breathing during sleep (66-68).

Eliot recruited well, and with individuals such as Noe Zamel, Art Slutsky and Greg Downey, respiratory research became strong at the University of Toronto.

\section{Jim Hogg and the University of British Columbia}

In 1977, Jim Hogg moved from McGill University to the University of British Columbia and St Paul's Hospital (Vancouver, British Columbia). He took Peter Paré, the son of the famous clinician, Peter Paré senior, who trained so many outstanding Canadian clinical respirologists. This was like the Boston Red Sox trading Babe Ruth to the New York Yankees. Like the Yankees when they got Ruth, research at the University of British Columbia and the Vancouver General Hospital was already making important contributions, particularly in occupational asthma by Moira Chan-Yeung (69-71). But Jim built a powerhouse at St Paul's Hospital, which supplanted the Vancouver General Hospital as the University of British Columbia's main centre for clinical investigation, and brought Vancouver to the forefront of respiratory research. Before they left Montreal, Jim and Peter, with Rick Boucher, had already published a landmark paper on bronchial epithelial permeability (72). Jim, who over a lifetime of research has made enormous contributions to our understanding of COPD, turned his attention, along with Peter, to the structure-function relationships in asthma, starting with their seminal paper on the pathophysiology of airway narrowing (73). This was the first of a series of important papers focusing on the roles of airway wall thickening, airway smooth muscle contractility and the load the smooth muscle acted on, in determining the excessive bronchoconstriction that characterizes asthma.

\section{Saskatchewan and Alberta}

Jim Dosman, who has made important contributions to the diagnosis of peripheral airway obstruction in smokers while in Montreal $(39,40,74)$, took up an academic appointment at the University of Saskatchewan (Saskatoon, Saskatchewan) and immediately established a program to study the respiratory effects of exposure to farm products, in general, and grain dust, in particular, in Canada's bread basket $(75,76)$. David Cotton and Don Cockcroft soon joined Jim in this endeavour. They showed chronic bronchitis and increased bronchial responsiveness to airway smooth muscle agonist in farm workers exposed to grain dust, even among nonsmokers (77-79). Jim is still very actively investigating the health effects of farm workers exposed to poultry facilities, swine confinement buildings and other adverse occupational exposures in the farming community. In doing so, Jim has made a major contribution to respiratory health on the Prairies and to farming communities across the country.

Malcolm King was the only native Canadian with a $\mathrm{PhD}$ when he came to Montreal for a postdoctoral fellowship. Trained as a physical chemist, he developed an ingenious micro method to measure the rheological properties of microlitres of mucus. This involved placing a tiny metal ball in a tiny blob of mucus, subjecting it to an alternating magnetic field and measuring the response of the ball in relation to the sinusoidally oscillating magnetic field. He measured the phase lag, a function of mucus viscosity, and the amplitude, a function of its elastic properties, at different frequencies $(80,81)$. For the first time, the rheological properties of normal tracheobronchial mucus (only available in tiny quantities) could be measured. He took this brilliant methodology with him when he went to the University of Alberta. There, he extended his methodology to correlate the relationship between rheological properties and mucociliary transport, using the transport of the mucus across the excised frog's palate combined with his microrheological technique $(82,83)$. When he assessed the rheological properties of cystic fibrosis (CF) mucus, he surprised everyone by showing that it was normal. It was only in purulent CF sputum that the elasticity and viscosity increased (84). However, CF mucus was transported more slowly across the frog's ciliated palate in vitro even though its rheological properties were essentially normal, so Malcolm postulated that there was some factor in CF mucus that interfered with ciliary beat function (84). Perhaps his research is the reason that $\mathrm{CF}$ is very rarely referred to as mucoviscidosis any more.

Bill Whitelaw, a McGill University graduate who did a postdoctoral fellowship with Milic-Emili, and who published the paper that recorded mouth pressure $0.1 \mathrm{~s}$ after starting to inspire against an occluded airway (a popular test of central respiratory drive [85]), took up a position in the new Faculty of Medicine at the University of Calgary (Calgary, Alberta). He, more than anyone, made the respiratory group at the University of Calgary the strong program that it is today. There, he published papers on the structure-function relationships of the diaphragm $(86,87)$. To my knowledge, he was the first to downplay the curvature of the diaphragm dome as an important source of transdiaphragmatic pressure, while he emphasized the importance of the diaphragm's length-tension characteristics (87). This implied that the diaphragm acted more as a piston than a section of a sphere, in which the transdiaphragmatic pressure was determined by the tension within its fibres and its radius of curvature. Thus, nearly 25 years ago, he proposed what at the time was an almost heretical view of diaphragm mechanics; today, it is widely accepted.

\section{Other Canadian contributions}

The retrograde catheter technique to measure pressure in small airways $(27,88)$ was used by Larry Wood to investigate the effect of gas physical properties on airway dynamics (89) and by Ludwig Engel as a gas sampling device to investigate intrapulmonary gas mixing (90-93). It was discovered that the interface between dead space and alveolar gas was dynamic, with alveolar gas extending into quite large airways throughout inspiration due to cardiogenic mixing. With increasing inspiratory flow, the interface moved distally while, when the airways dilated, it moved centrally.

Bob Brown's discovery as a medical student that airway obstruction had no effect on either static or dynamic elastic properties in excised dog lobes (34) meant that air flowed through collateral channels to maintain a normal tidal volume of airspaces beyond the obstructed segments. Because this was so, even at a breathing frequency of 60 breaths/min, collateral ventilation had to be surprisingly rapid. This, combined with 
Jim Hogg's findings that collateral flow resistance (28) was less than airways resistance in emphysema, led to an extensive investigation of collateral ventilation (94-99). As a result, it became evident that the pathophysiological effect of airways obstruction could not be understood without taking the influence of collateral ventilation into account. These effects minimized the mechanical abnormalities, but ventilation distribution and gas exchange remained abnormal $(97,98)$.

Jim Martin, who came to Canada from Ireland via Johns Hopkins University, working with Ludwig Engel, Mike Habib and Stephanie Shore, discovered intrinsic positive end-expiratory pressure (PEEP) a few years before it was called that. They found that dynamic hyperinflation induced in normal subjects by expiratory loads was accompanied by a marked increase in nondiaphragmatic inspiratory muscle work (94), resulting in a sustained contraction of these muscles throughout the whole respiratory cycle. Following this, they investigated the effect of continuous positive airway pressure (CPAP) in asthmatics during agonist-induced bronchoconstriction (100). CPAP hardly changed lung volume but markedly decreased inspiratory work and pressure. CPAP replaced the intrinsic PEEP with external PEEP, thereby relieving the inspiratory muscles of a large part of the load they were sustaining. Another important contribution to airway physiology was the discovery by Charlie Irvin during a postdoctoral fellowship at McGill University, of bronchodilation by stimulating the nonadrenergic, noncholinergic part of the vagus nerve in bronchoconstricted cats (101). This was the first in vivo demonstration of purinergic bronchodilation.

Clinical investigators in Canada have made important contributions to the physiology and pathophysiology of the ventilatory pump since the mid-1970s and this has continued to the present day. These studies fall into two main categories: the mechanical linkage and coordination between the various muscles, which displace the chest wall and ventilate the lung; and the effects of respiratory muscle fatigue and expiratory flow-limitation on respiratory muscle actions and control. As I have done throughout this review, I focused on contributions made 25 or more years ago.

Investigation of the mechanical linkage and coordination of the respiratory muscles began with the description of the diaphragm as two muscles, the crural and costal parts, with different actions on innervation of the cervical nerve root and different mechanical linkage with other respiratory muscles (102). The two parts were modelled as being mechanically in parallel so that the total force developed by the diaphragm was the sum of the individual forces generated by each part. The crural diaphragm was mechanically in series with the nondiaphragmatic inspiratory muscles of the rib cage, whereas the costal diaphragm was mechanically in parallel (103). Thus the volume displaced by simultaneous contraction of the rib cage muscles and the crural part was the sum of the individual muscle's contribution, but the forces they developed were the same. In contrast, the force developed by the costal part summed with the force developed by the rib cage muscles to produce the total force developed, but the volume contributions were shared and were identical. Viewed as a whole then, the diaphragm was partly in series and partly in parallel with the inspiratory rib cage muscles, adding both to the volumes displaced and the forces developed by these muscles.

When it was shown that it was a relatively simple task to produce fatigue of the diaphragm and global inspiratory muscle fatigue in healthy subjects by increasing energy demands $(104,105)$ and, in dogs, by decreasing energy supplies $(106)$, it became apparent that when total body energy supplies were inadequate to meet total body energy demands, competition developed between the respiratory muscles and other body tissues for available energy supplies $(107,108)$. While this may be important pathophysiologically in cardiogenic and hemorrhagic shock (106), another Canadian working in the United States, Jerry Dempsey, and his colleagues, have recently shown that it is an important factor limiting exercise in healthy people (109).

Attention then turned to the possibility that fatigue was an important cause of hypercapnic respiratory failure and how to establish a diagnosis. Francois Bellemare and Alex Grassino published their renowned paper on the diaphragmatic tension time index, calculated as the product of the duty cycle and transdiaphragmatic pressure and expressed as a fraction of maximal transdiaphragmatic pressure (110). When this product was greater than 0.15 , fatigue developed. When less than 0.15 , fatigue did not occur. The threshold for diaphragmatic fatigue was established. It was shown that fatigue could be detected by assessing diaphragmatic contractility with bilateral phrenic nerve stimulation (111) and by measuring a shift in the power spectrum of the diaphragmatic electromyogram with a decrease in high frequency power relative to low frequency power (112). In spite of these advances, the role of diaphragmatic and global inspiratory muscle fatigue in exercise limitation and respiratory failure has remained elusive. It now seems likely that fatigue is not an important source of respiratory failure, except perhaps during weaning failure and cardiogenic shock. More probably, when faced with the development of fatigue due to an imbalance between respiratory muscle energy supply and demand, carbon dioxide retention occurs before fatigue develops to prevent force failure in noniatrogenic permissive hypercapnia as it were.

\section{CONCLUSIONS}

The contributions of Canadians and other scientists working in Canada to respiratory physiology and pathophysiology were, and are, far greater than could be predicted from a country with a population only one-tenth that of our neighbours to the south. During the last half of the 20th century, and now into the next millennium, Jonathan Meakins, Ronald Christie, Joe Doupe, Reuben Cherniack and David Bates have left us an extraordinary legacy of which all Canadians can be enormously proud. It will be up to someone else, someday, to write our history over the past 25 years. Then the more recent contributions of many younger scientists such as Andrew Halayko, Greg Downey, Francois Maltais, Denis O'Donnell, Doug Bradley, Qutayba Hamid, Basil Petrof, John Remmers, Allan Becker, Michel Laviolette, Louis-Phillipe Boulet, Yves Cormier, Magde Younes, Paul O'Byrne and many others, will be in the spotlight. With these people and their colleagues doing an outstanding job carrying Canada's torch, the future is not in doubt. We will remain world leaders in respiratory research.

\section{REFERENCES}

1. Christie RV. The lung volume and its subdivisions: I. Methods of measurement. J Clin Invest 1932;11:1099-118.

2. Christie RV, McIntosh CA. The measurement of the intrapleural pressure in man and its significance. J Clin Invest 1934;13:279-94.

3. Christie RV. The elastic properties of the emphysematous lung and their clinical significance. J Clin Invest 1934;13:295-321. 
4. Christie RV, Meakins JC. The intrapleural pressure in congestive heart failure and its clinical significance. J Clin Invest 1934;13:323-45.

5. Christie RV, Eldridge FL, Mcllroy MB, Thomas JP. The effect of added elastic and non-elastic resistances on the pattern of breathing in normal subjects. Clin Sci (Lond) 1956;15:337-44.

6. Cherniack RM. The physical properties of the lung in chronic obstructive pulmonary emphysema. J Clin Invest 1956;35:394-404.

7. Campbell EJ, Westlake EK, Cherniack RM. Simple methods of estimating oxygen consumption and efficiency of the muscles of breathing. J Appl Physiol 1957;11:303-8.

8. Campbell EJ, Westlake EK, Cherniack RM. The oxygen consumption and efficiency of the respiratory muscles of young male subjects. Clin Sci (Lond) 1959;18:55-64.

9. Levison H, Cherniack RM. Ventilatory cost of exercise in chronic obstructive pulmonary disease. J Appl Physiol 1968;25:21-7.

10. Cherniack RM. The oxygen consumption and efficiency of the respiratory muscles in health and emphysema. J Clin Invest 1959;38:494-9.

11. Ball WC Jr, Stewart PB, Newsham LG, Bates DV. Regional pulmonary function studied with xenon 133 . J Clin Invest 1962;41:519-31.

12. Bryan AC, Bentivoglio LG, Beerel F, MacLeish H, Zidulka A, Bates DV. Factors affecting regional distribution of ventilation and perfusion in the lung. J Appl Physiol 1964;19:395-402.

13. Bohn DJ, Miyasaka K, Marchak BE, Thompson WK, Froese AB, Bryan AC. Ventilation by high-frequency oscillation. J Appl Physiol 1980;48:710-6.

14. Froese $A B$, Bryan AC. High frequency ventilation. Am Rev Respir Dis 1981;123:249-50.

15. Hamilton PP, Onayemi A, Smyth JA, et al. Comparison of conventional and high-frequency ventilation: Oxygenation and lung pathology. J Appl Physiol 1983;55:131-8.

16. Bryan AC, Slutsky AS. Long volume during high frequency oscillation. Am Rev Respir Dis 1986;133:928-30.

17. Bryan AC, Froese AB. Reflections on the HIFI trial. Pediatrics 1991;87:565-7.

18. Milic-Emili J, Henderson JA, Dolovich MB, Trop D, Kaneko K. Regional distribution of inspired gas in the lung. J Appl Physiol 1966;21:749-59.

19. McCarthy DS, Spencer R, Greene R, Milic-Emili J. Measurement of "closing volume" as a simple and sensitive test for early detection of small airway disease. Am J Med 1972;52:747-53.

20. Kaneko K, Milic-Emili J, Dolovich MB, Dawson A, Bates DV. Regional distribution of ventilation and perfusion as a function of body position. J Appl Physiol 1966;21:767-77.

21. Bryan AC, Milic-Emili J, Pengelly D. Effect of gravity on the distribution of pulmonary ventilation. J Appl Physiol 1966;21:778-84.

22. Anthonisen NR, Smith HJ. Respiratory acidosis as a consequence of pulmonary edema. Ann Intern Med 1965;62:991-9.

23. Anthonisen NR, Dolovich MB, Bates DV. Steady state measurement of regional ventilation to perfusion ratios in normal man. J Clin Invest 1966;45:1349-56.

24. Bass H, Heckscher T, Anthonisen NR. Regional pulmonary gas exchange in patients with pulmonary embolism. Clin Sci 1967:33:355-64.

25. Bass H, Henderson JA, Heckscher T, Oriol A, Anthonisen NR. Regional structure and function in bronchiectasis. A correlative study using bronchography and 133Xe. Am Rev Respir Dis 1968;97:598-609.

26. Anthonisen NR, Bass H, Oriol A, Place RE, Bates DV. Regional lung function in patients with chronic bronchitis. Clin Sci $1968 ; 35: 495-511$.

27. Hogg JC, Macklem PT, Thurlbeck WM. Site and nature of airway obstruction in chronic obstructive lung disease. N Engl J Med 1968;278:1355-60.

28. Hogg JC, Macklem PT, Thurlbeck WM. The resistance of collateral channels in excised human lungs. J Clin Invest 1969;48:421-31.

29. Choong CK, Macklem PT, Pierce JA, et al. Transpleural ventilation of explanted human lungs. Thorax 2007;62:623-30.

30. Hogg JC, Nepszy S. Regional lung volume and pleural pressure gradient estimated from lung density in dogs. J Appl Physiol 1969;27:198-203.

31. Coxson HO, Mayo JR, Behzad H, et al. Measurement of lung expansion with computed tomography and comparison with quantitative histology. J Appl Physiol 1995;79:1525-30.
32. Mead J. The lung's "quiet zone". N Engl J Med 1970;282:1318-9.

33. Woolcock AJ, Vincent NJ, Macklem PT. Frequency dependence of compliance as a test for obstruction in the small airways. J Clin Invest 1969;48:1097-106.

34. Brown R, Woolcock AJ, Vincent NJ, Macklem PT. Physiological effects of experimental airway obstruction with beads. J Appl Physio 1969;27:328-35

35. Levine G, Housley E, MacLeod P, Macklem PT. Gas exchange abnormalities in mild bronchitis and asymptomatic asthma. N Engl J Med 1970;282:1277-82.

36. Flenley DC, Picken J, Welchel L, Ruff F, Corry PM, Macklem PT Blood gas transfer after small airway obstruction in the dog and minipig. Respir Physiol 1972;15:39-51.

37. Hutcheon M, Griffin P, Levison H, Zamel N. Volume of isoflow. A new test in detection of mild abnormalities of lung mechanics. Am Rev Respir Dis 1974;110:458-65.

38. Martin RR, Lindsay D, Despas P, et al. The early detection of airway obstruction. Am Rev Respir Dis 1975;111:119-25.

39. Dosman J, Bode F, Urbanetti J, Martin R, Macklem PT. The use of a helium-oxygen mixture during maximum expiratory flow to demonstrate obstruction in small airways in smokers. J Clin Invest 1975;55:1090-9.

40. Bode FR, Dosman J, Martin RR, Macklem PT. Reversibility of pulmonary function abnormalities in smokers. A prospective study of early diagnostic tests of small airways disease. Am J Med 1975;59:43-52

41. Stephens NL, Kroeger E, Mehta JA. Force-velocity characteristics of respiratory airway smooth muscle. J Appl Physiol 1969;26:685-92.

42. Stephens NL, Chiu BS. Mechanical properties of tracheal smooth muscle and effects of $\mathrm{O}_{2}, \mathrm{CO}_{2}$, and $\mathrm{pH}$. Am J Physiol 1970;219:1001-8.

43. Antonissen LA, Mitchell RW, Kroeger EA, Kepron W, Tse KS, Stephens NL. Mechanical alterations of airway smooth muscle in a canine asthmatic model. J Appl Physiol 1979;46:681-7.

44. Chernick V, Vidyasagar D. Continuous negative chest wall pressure in hyaline membrane disease: One year experience. Pediatrics 1972;49:753-60.

45. Chernick V. Hyaline-membrane disease: Therapy with constant lung-distending pressure. N Engl J Med 1973;289:302-4

46. Berg TJ, Pagtakhan RD, Reed MH, Langston C, Chernick V. Bronchopulmonary dysplasia and lung rupture in hyaline membrane disease: Influence of continuous distending pressure. Pediatrics 1975;55:51-4.

47. Killian KJ, Campbell EJ, Howell JB. The effect of increased ventilation on resistive load discrimination. Am Rev Respir Dis 1979;120:1233-8.

48. Killian KJ, Mahutte CK, Howell JB, Campbell EJ. Effect of timing, flow, lung volume, and threshold pressures on resistive load detection. J Appl Physiol 1980;49:958-63.

49. Stubbing DG, Killian KJ, Campbell EJ. The quantification of respiratory sensations by normal subjects. Respir Physiol 1981;44:251-60.

50. Killian KJ, Bucens DD, Campbell EJ. Effect of breathing patterns on the perceived magnitude of added loads to breathing J Appl Physiol 1982;52:578-84.

51. Burdon JG, Juniper EF, Killian KJ, Hargreave FE, Campbell EJ. The perception of breathlessness in asthma. Am Rev Respir Dis 1982;126:825-8.

52. Killian KJ, Campbell EJ. Dyspnea and exercise. Annu Rev Physiol 1983;45:465-79.

53. Stubbing DG, Killian KJ, Campbell EJ. Weber's law and resistive load detection. Am Rev Respir Dis 1983;127:5-7.

54. Jones NL, Rebuck AS. Rebreathing equilibration of $\mathrm{CO}_{2}$ during exercise. J Appl Physiol 1973;35:538-41.

55. Jones NL. Mixed venous carbon dioxide tension measured by rebreathing. Can Med Assoc J 1978;118:476.

56. Jones NL. New tests to assess lung function. Exercise testing in pulmonary evaluation: Rationale, methods and the normal respiratory response to exercise. N Engl J Med 1975;293:541-4.

57. Jones NL. New tests to assess lung function. Exercise testing in pulmonary evaluation: Clinical applications. N Engl J Med 1975;293:647-50

58. Ryan WJ, Sutton JR, Toews CJ, Jones NL. Metabolism of infused L(+)-lactate during exercise. Clin Sci (Lond) 1979;56:139-46.

59. Jones NL. Hydrogen ion balance during exercise. Clin Sci (Lond) 1980;59:85-91. 
60. Jones NL, Ehrsam RE. The anaerobic threshold. Exerc Sport Sci Rev 1982;10:49-83.

61. Jones NL, Heigenhauser GJ, Kuksis A, Matsos CG, Sutton JR, Toews CJ. Fat metabolism in heavy exercise. Clin Sci (Lond) 1980;59:469-78.

62. Phillipson EA, Murphy E, Kozar LF. Regulation of respiration in sleeping dogs. J Appl Physiol 1976;40:688-93.

63. Phillipson EA, Kozar LF, Rebuck AS, Murphy E. Ventilatory and waking responses to $\mathrm{CO}_{2}$ in sleeping dogs. Am Rev Respir Dis 1977;115:251-9.

64. Phillipson EA, Sullivan CE, Read DJ, Murphy E, Kozar LF. Ventilatory and waking responses to hypoxia in sleeping dogs. J Appl Physiol 1978;44:512-20.

65. Sullivan CE, Kozar LF, Murphy E, Phillipson EA. Primary role of respiratory afferents in sustaining breathing rhythm. J Appl Physiol 1978;45:11-7.

66. Phillipson EA. Regulation of breathing during sleep. Am Rev Respir Dis 1977;115:217-24.

67. Phillipson EA. Respiratory adaptations in sleep. Annu Rev Physiol 1978;40:133-56.

68. Phillipson EA. Control of breathing during sleep. Am Rev Respir Dis 1978;118:909-39.

69. Chan-Yeung M, Barton GM, McLean L, Grzybowski S. Bronchial reactions to western red cedar (Thuja plicata). Can Med Assoc J $1971 ; 105: 56-8$.

70. Chan-Yeung M, Barton GM, MacLean L, Grzybowski S. Occupational asthma and rhinitis due to Western red cedar (Thuja plicata). Am Rev Respir Dis 1973;108:1094-102.

71. Chan-Yeung M. Fate of occupational asthma. A follow-up study of patients with occupational asthma due to Western Red Cedar (Thuja plicata). Am Rev Respir Dis 1977;116:1023-9.

72. Hogg JC, Pare PD, Boucher RC. Bronchial mucosal permeability. Fed Proc 1979;38:197-201.

73. Moreno RH, Hogg JC, Paré PD. Mechanics of airway narrowing. Am Rev Respir Dis 1986;133:1171-80.

74. Dosman J, Macklem PT. Disease of small airways. Adv Intern Med 1977;22:355-76.

75. Dosman JA. Preventive diagnosis in occupational pulmonary disease. Ann Intern Med 1975;83:274-6.

76. Dosman JA. Chronic obstructive pulmonary disease and smoking in grain workers. Ann Intern Med 1977;87:784-6.

77. Cotton DJ, Dosman JA. Grain dust and health. III. Environmental factors. Ann Intern Med 1978;89:420-1.

78. Mink JT, Gerrard JW, Cockcroft DW, Cotton DJ, Dosman JA. Increased bronchial reactivity to inhaled histamine in nonsmoking grain workers with normal lung function. Chest $1980 ; 77: 28-31$

79. Dosman JA, Cotton DJ, Graham BL, Li KY, Froh F, Barnett GD. Chronic bronchitis and decreased forced expiratory flow rates in lifetime nonsmoking grain workers. Am Rev Respir Dis 1980;121:11-6.

80. King M, Macklem PT. Rheological properties of microliter quantities of normal mucus. J Appl Physiol 1977;42:797-802.

81. King M. Viscoelastic properties of airway mucus. Fed Proc 1980;39:3080-5.

82. King M. Interrelation between mechanical properties of mucus and mucociliary transport: Effect of pharmacologic interventions. Biorheology 1979;16:57-68.

83. King M. Relationship between mucus viscoelasticity and ciliary transport in guaran gel/frog palate model system. Biorheology 1980;17:249-54.

84. King M. Is cystic fibrosis mucus abnormal? Pediatr Res 1981;15:120-2.

85. Whitelaw WA, Derenne JP, Milic-Emili J. Occlusion pressure as a measure of respiratory center output in conscious man. Respir Physiol 1975;23:181-99.
86. Guenter CA, Whitelaw WA. The role of diaphragm function in disease. Arch Intern Med 1979;139:806-8.

87. Whitelaw WA, Hajdo LE, Wallace JA. Relationships among pressure, tension, and shape of the diaphragm. J Appl Physiol 1983;55:1899-905

88. Macklem PT, Mead J. Resistance of central and peripheral airways measured by a retrograde catheter. J Appl Physiol 1967;22:395-401.

89 Wood LD, Engel LA, Griffin P, Despas P, Macklem PT. Effect of gas physical properties and flow on lower pulmonary resistance. J Appl Physiol 1976;41:234-44.

90. Engel LA, Wood LD, Utz G, Macklem PT. Gas mixing during inspiration. J Appl Physiol 1973;35:18-24.

91. Engel LA, Menkes H, Wood LD, Utz G, Joubert J, Macklem PT. Gas mixing during breath holding studied by intrapulmonary gas sampling. J Appl Physiol 1973;35:9-17.

92. Fukuchi Y, Roussos CS, Macklem PT, Engel LA. Convection, diffusion and cardiogenic mixing of inspired gas in the lung; an experimental approach. Respir Physiol 1976;26:77-90.

93. Engel LA, Macklem PT. Gas mixing and distribution in the lung. Int Rev Physiol 1977;14:37-82.

94. Martin JG, Habib M, Engel LA. Inspiratory muscle activity during induced hyperinflation. Respir Physiol 1980;39:303-13.

95. Woolcock AJ, Macklem PT. Mechanical factors influencing collateral ventilation in human, dog, and pig lungs. J Appl Physiol 1971;30:99-115.

96. Menkes H, Gardiner A, Gamsu G, Lempert J, Macklem PT. Influence of surface forces on collateral ventilation. J Appl Physiol 1971;31:544-9

97. Flenley DC, Welchel L, Macklem PT. Factors affecting gas exchange by collateral ventilation in the dog. Respir Physiol $1972 ; 15: 52-69$

98. Hogg W, Brunton J, Kryger M, Brown R, Macklem P. Gas diffusion across collateral channels. J Appl Physiol 1972;33:568-75.

99. Macklem PT. Airways obstruction and collateral ventilation. Physiol Rev 1971;51:368-436.

100. Martin JG, Shore S, Engel LA. Effect of continuous positive airway pressure on respiratory mechanics and pattern of breathing in induced asthma. Am Rev Respir Dis 1982;126:812-7.

101. Irvin CG, Boileau R, Tremblay J, Martin RR, Macklem PT. Bronchodilatation: Noncholinergic, nonadrenergic mediation demonstrated in vivo in the cat. Science 1980;207:791-2.

102. De Troyer A, Sampson M, Sigrist S, Macklem PT. The diaphragm: Two muscles. Science 1981;213:237-8.

103. Macklem PT, Macklem DM, De Troyer A. A model of inspiratory muscle mechanics. J Appl Physiol 1983;55:547-57.

104. Roussos CS, Macklem PT. Diaphragmatic fatigue in man. J Appl Physiol 1977;43:189-97.

105. Roussos C, Fixley M, Gross D, Macklem PT. Fatigue of inspiratory muscles and their synergic behavior. J Appl Physiol 1979;46:897-904.

106. Aubier M, Trippenbach T, Roussos C. Respiratory muscle fatigue during cardiogenic shock. J Appl Physiol 1981;51:499-508.

107. Field S, Kelly SM, Macklem PT. The oxygen cost of breathing in patients with cardiorespiratory disease. Am Rev Respir Dis $1982 ; 126: 9-13$

108. Roussos C, Macklem PT. The respiratory muscles. N Engl J Med 1982;307:786-97.

109. Dempsey JA, Harms CA, Ainsworth DM. Respiratory muscle perfusion and energetics during exercise. Med Sci Sports Exerc 1996;28:1123-8.

110. Bellemare F, Grassino A. Effect of pressure and timing of contraction on human diaphragm fatigue. J Appl Physiol 1982;53:1190-5.

111. Aubier M, Farkas G, De Troyer A, Mozes R, Roussos C. Detection of diaphragmatic fatigue in man by phrenic stimulation. J Appl Physiol 1981;50:538-44.

112. Gross D, Grassino A, Ross WR, Macklem PT. Electromyogram pattern of diaphragmatic fatigue. J Appl Physiol 1979;46:1-7. 


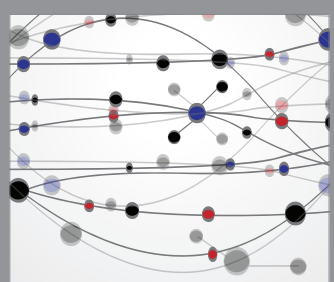

The Scientific World Journal
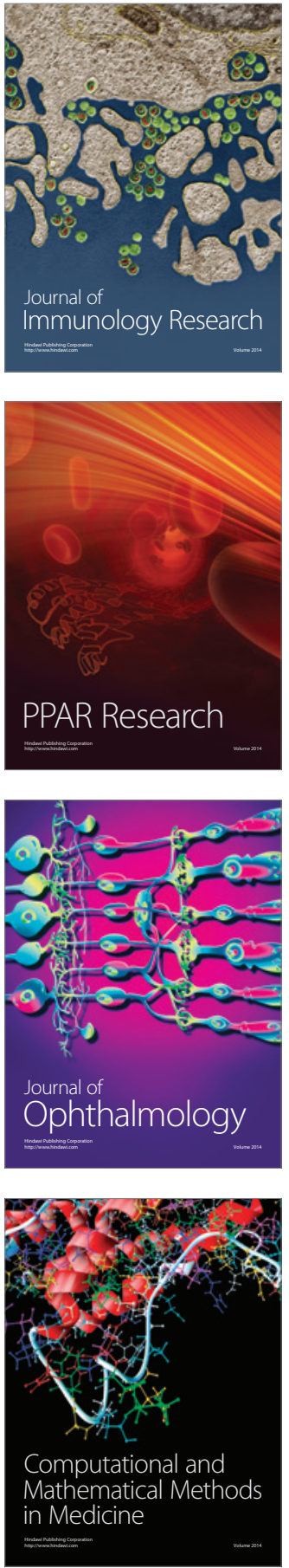

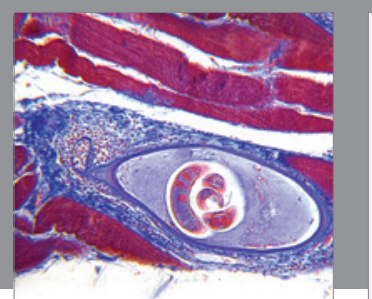

Gastroenterology Research and Practice

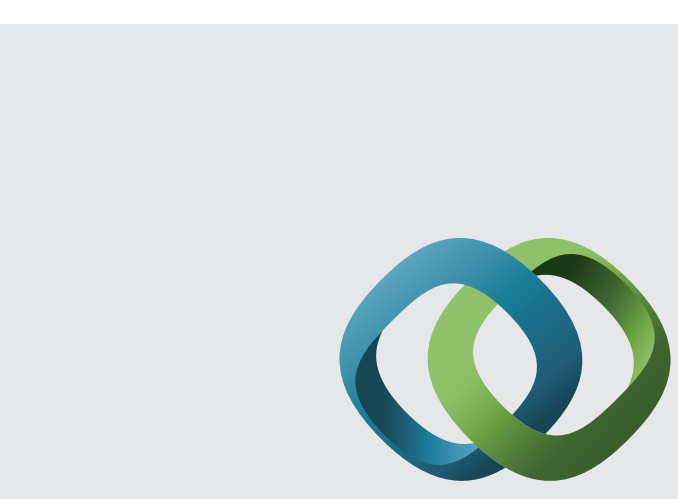

\section{Hindawi}

Submit your manuscripts at

http://www.hindawi.com
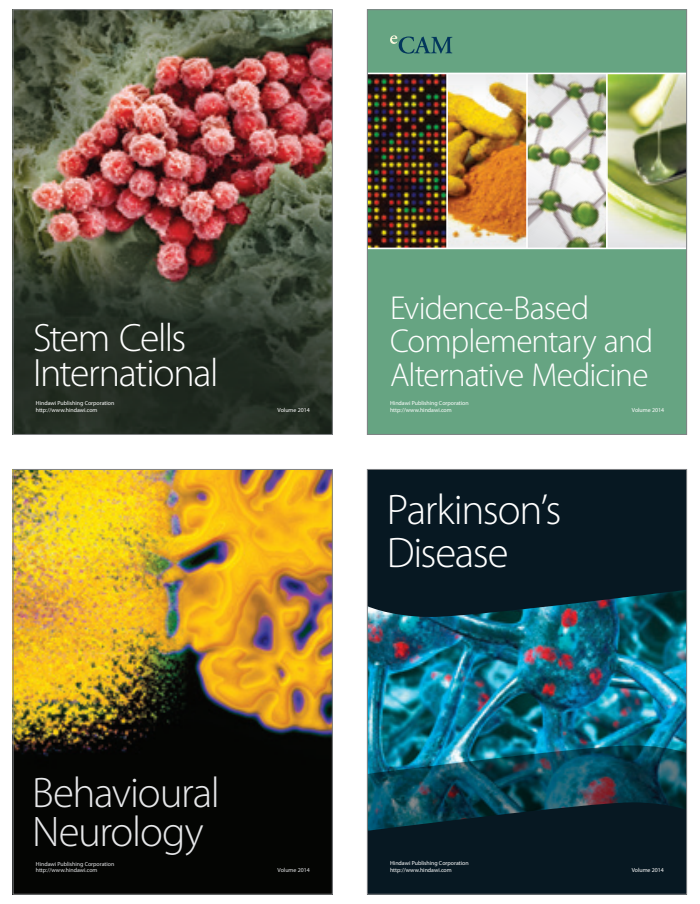
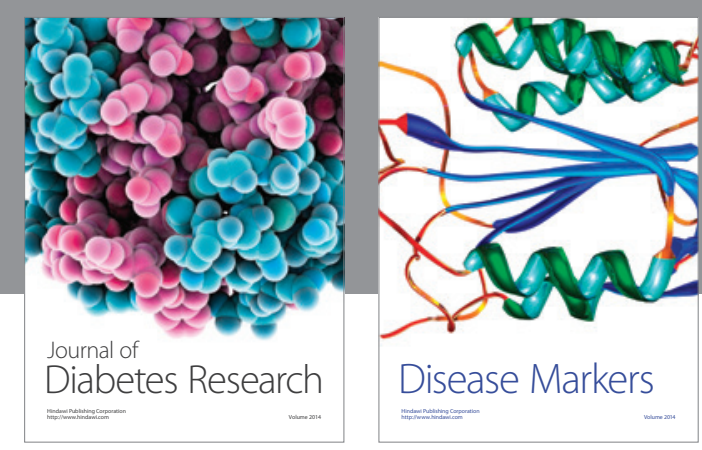

Disease Markers
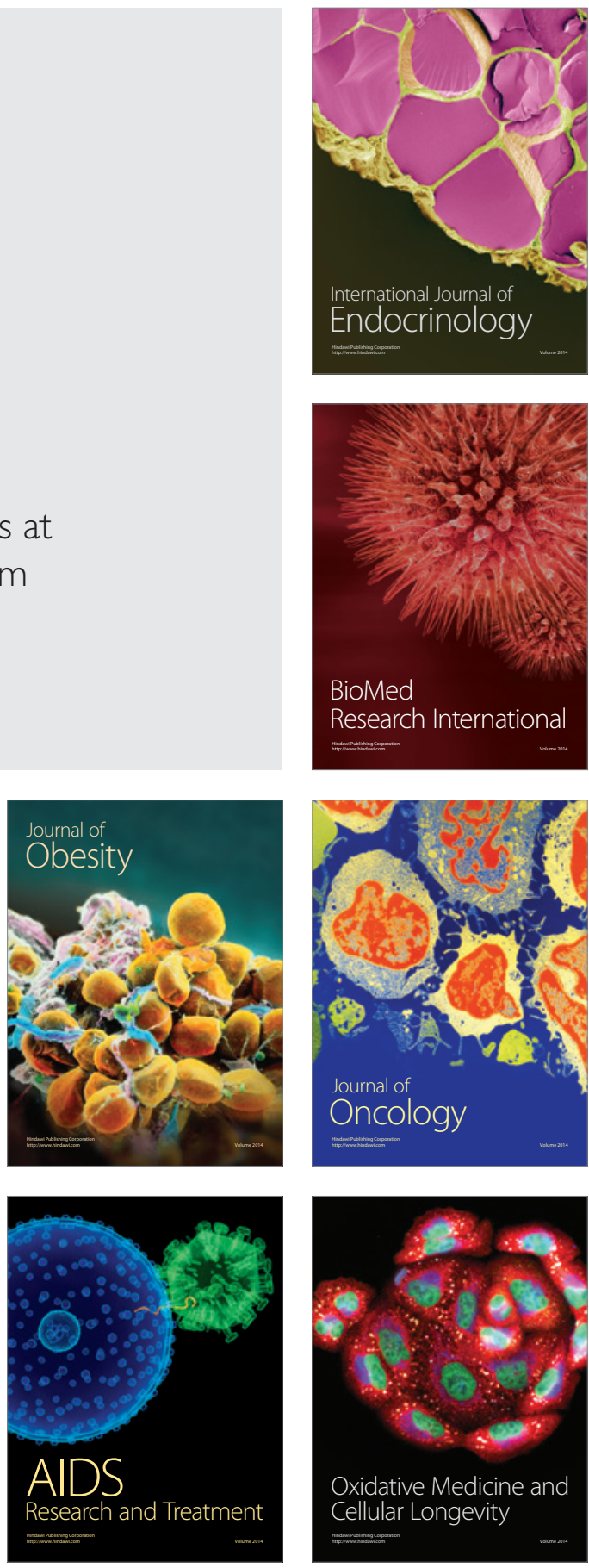